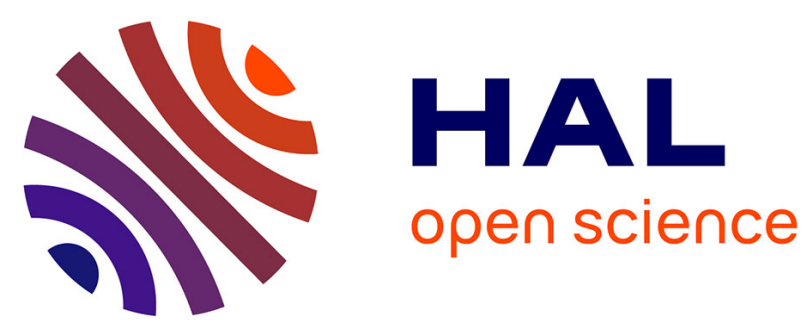

\title{
Simulation and Optimization Models in a Business Game for Decision-Making in Logistics Processes
}

Marco Aurelio Butzke, Anete Alberton, Jeancarlo Visentainer, Solimar Garcia, Irenilza De Alencar Nääs

\section{To cite this version:}

Marco Aurelio Butzke, Anete Alberton, Jeancarlo Visentainer, Solimar Garcia, Irenilza De Alencar Nääs. Simulation and Optimization Models in a Business Game for Decision-Making in Logistics Processes. IFIP International Conference on Advances in Production Management Systems (APMS), Sep 2016, Iguassu Falls, Brazil. pp.351-359, 10.1007/978-3-319-51133-7_42 . hal-01615730

\author{
HAL Id: hal-01615730 \\ https://hal.inria.fr/hal-01615730
}

Submitted on 12 Oct 2017

HAL is a multi-disciplinary open access archive for the deposit and dissemination of scientific research documents, whether they are published or not. The documents may come from teaching and research institutions in France or abroad, or from public or private research centers.
L'archive ouverte pluridisciplinaire HAL, est destinée au dépôt et à la diffusion de documents scientifiques de niveau recherche, publiés ou non, émanant des établissements d'enseignement et de recherche français ou étrangers, des laboratoires publics ou privés. 


\title{
Simulation and Optimization Models in a Business Game for Decision-making in Logistics Processes
}

\author{
Marco Aurelio Butzke ${ }^{1 \star}$, Anete Alberton ${ }^{2}$, Jeancarlo Visentainer ${ }^{1}$, Solimar \\ Garcia $^{3}$, and Irenilza de Alencar Nääs ${ }^{3}$ \\ 1 Unidavi, Rio do Sul, Brazil \\ \{marco, jv\}@unidavi.edu.br \\ ${ }^{2}$ Univali, Itajaí, Brazil \\ ${ }^{3}$ UNIP, São Paulo, Brazil

\begin{abstract}
Business games using simulation and optimization models can help users to find out solutions to complex management problems and develop critical and strategic thinking skills. The main goal of this paper is to present the application of a business game provided with a simulation and optimization model for decision-making in logistics processes, including total cost, calculated results of costs and trade-offs involved in the logistics business operations. Furthermore, it is expected that the developed models can contribute to the use of business games in teaching and learning process with a focus on professional preparation of students for the labor market. In the end, it is observed that this tool may be useful for training professionals and students.
\end{abstract}

Keywords: Business games $\cdot$ Logistic processes $\cdot$ Optimization

\section{Introduction}

The importance of applying business games as a teaching strategy can help to evaluate students' results, and analyze the perceptions of a pedagogical tool in the teaching process, from the perspective of the knowledge, acquired and the content of learning with interaction and immediate feedback. Simulations and business games have produced a substantial impact on concepts and teaching applications and help overcome limitations of traditional methods [1].

In 2010 , the cost of managing the global supply chain reached between $7.7 \%$ and $9.3 \%$ of GDP [2]. Therefore, any small improvement in the chain has the potential benefit to society, which is why the modeling and analysis of logistics systems stimulated worldwide interest [3].

The simulation technologies have proven to be a great tool for modeling complex environments [4]. One kind of simulation for processes involving logistics and production is the business game [5]. The simulations can help analyzing

\footnotetext{
* The authors wish to thank CAPES and CNPQ, and the Universitat Politècnica de València (UPV).
} 
the resulting events of logistical decisions and how they influence on the costs and their impact on organizational performance in a controlled environment to conduct experiments without risk or loss $[6,7]$. Business games blend skill, opportunity, and strategy to simulate aspects of reality [8].

Simulation softwares have high ability to replicate uncertainty, especially when it comes from discrete event simulation in which can handle the variability and uncertainties [9]. Despite these advantages, there are few examples of simulation games in supply chain education, whose main example is the Beer game that was introduced by MIT in 1960 as an industrial dynamic exercise [10]. The aim of this paper is to present the application of a simulation and optimization model in a business game for decision-making in logistics processes.

\section{Theoretical Framework}

Simulations challenge users to find out solutions for complex management problems, therefore they develop their critical and strategic thinking skills; if teachers aim to prepare students for the labor market, business games can contribute to improve students learning [11]. The simulation technologies have proven to be a competent way to analyze complex systems, allowing the changes and effects of processes and presenting predictions in a simpler way [4].

Deling et al. presented the analysis of logistics problems, considering the distribution and allocation of resources through a simulation model combined with optimization and showed the advantages of this method compared to simple mathematical analytic method to study the location of distribution centers [12]. As a kind of combination of modeling simulation and optimization methods to solve the problem of location regarding the distribution center was presented to Thiers and Mcginnis [3]. According to the authors, this solution depends on the optimization of the system and there is no mathematical formula that can express the decision variables, and can be proved as an effective tool to solve such problems. The study of Feng and Ma, Arisha et al. $[8,13]$ shows that the simulation method is closer to the real situation when applied to the location of distribution centers compared to the analytical method.

The optimization models applied to business games can help produce the best answers to the simulated problems in a given scenario [14]. The decision variables in the optimization model serve as ideal parameters to help in decision-making when using simulation softwares [11].

The construction of a simulation model must be based on answering important questions to provide fast and lower cost responses, resulting in a powerful and useful tool to improve the decision-making process. The impact analysis is a differential in the simulation process.

Business game as one of the types of simulation for processes involving logistics and production; therefore, managers can work in a simulated world interactively [5]. Simulations in logistics, especially in supply chain management have already been applied for a long time. The Beer Game, one of the most 
common in logistics, helps students to manage an efficient supply chain and to solve problems [15].

Davis et al. [16] shows the use of web application for games as a quality educational tool also for the supply chain, which encourages collaborative learning. The development of online technologies, particularly social networks, including improvements in the form of interaction between students that can be made into high-quality virtual environments [17], besides the advantage of being cheaper than simulation through softwares [14].

The application of online simulation games to teach supply chain management allows students to actively participate in the learning process, as well recognize the impact of their decisions on the execution of activities [8]. Modeling and simulation are the appropriate tools to measure cost reduction, increase gains between each step and measure the effects of these relationships predicting the possible outcomes before implementing a new process. Likewise, modeling and simulation identify points of improvement aiming to optimize them.

Optimization models can help to produce the best responses to simulated problems in a scenario [3]; decision variables in optimization model serve as optimum parameters to complement decision-making on applications for simulation use [12]. The optimization models when used in conjunction with simulated scenarios can contribute to the learning process of the participants of business games, which are proposed in modeled experimental environments in a simplified way $[12,6]$. However, business games must reflect the complexity of the reality of modern business, where decisions have to be taken in a systematic and integrated way.

\section{Methodology}

This descriptive and qualitative research analyzed the decision-making process in logistics processes and proposed a solution through a business game, addressed by simulation and optimization models developed in previous studies $[18,4]$, which classifies itself as deductive research regarding outcomes that was applied in a business game called Entersim created to contribute to the teaching and learning process.

Regarding the logic, this research is classified as applied because it uses the findings to existing problems through the implementation of simulation and optimization models in a business game considering the decision-making scenario in logistics processes. In relation to the result, we can classify the research as deductive considering a model was developed from existing theories and concepts, and implemented in business games for contributing to the teaching and learning process.

The construction of a simulation model must be based on answering important questions to provide rapid and lower cost responses, resulting in a useful and appropriate tool. The optimization models, when used together with simulated scenarios can contribute to the learning of participants in a business game. In the proposed game metrics were defined for calculating the logistics costs of supply 
and distribution, product manufacturing, plant, and the acquisition value of raw materials. In addition, it was established efficiency levels and delivery times of raw materials and finished products, complemented by invoice delivered orders. Students could use the following options in decision-making toward logistics processes: manufacturing plant, production framework, supplier selection, transport modes for supply and distribution, freight, acquisition of lots, invoicing orders and stocks inventory.

The business game Entersim is developed on the Internet on a centralized server, Cloud Computing at Jelastic. The proposed simulation and optimization models intend to complement the use of business games to assist decision-making in an environment of complexity, with immediate feedback and the challenge of achieving the optimized proposed goal through a mathematical model.

\section{Implementation of Simulation and Optimization Models in a Business Game}

The business game Entersim was designed to be used as a simulator of environments in a company, which involves the company functions and organizational levels, whose business model used was a medium-sized company manufacturer of jeans, which manufactures six products, uses three categories of raw materials and receives orders from 27 Brazilian capitals such as business model. Based on simulated data, students choose the location of the plant installation and logistics related to the acquisition of raw materials and delivery of orders previously demanded, as well as the adjustments necessary in the production framework. Index and set of index represent the entities that set the model, such as products, cities, working days, production units, modes of transport and raw materials, which will be subject to the decision-making. The parameters are information that is fed into the process of simulation.

The results of the application of the formulas were produced from the decision variables that served as a basis for decision-making in the business game simulation process and the generation of the results of the optimization model performed to find out the better solution between the possibilities of the presented scenario.

The simulation model developed in business games allows experiments in a fictional situation, as well are used for training people to improve decisionmaking in complex and dynamic environments, in order to gain experience to perform in the labor market.

The determination of amounts related to logistics costs proposed in the business game simulator are the following ones: Gross revenue, Cost of raw material acquisition, Inbound cost, Raw material stock, Labor cost, Fixed cost, Leasing manufacturing plant, Outbound cost and Finished goods stock. Next, it will be presented the optimization model designed for parallel use to the business game. The model implemented in the business game to simulate decision-making in logistics processes is shown in Figure 11. 


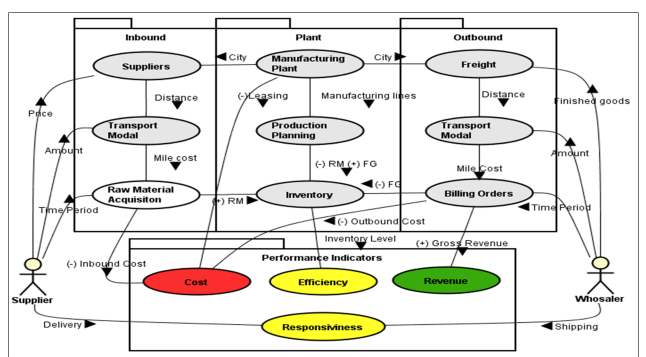

Fig. 1. Simulation Model for Business Game

The construction of the optimization model was initiated by the logistic plant process, in which it was determined the quantity of product to be produced in the day and per unit of production. In the optimization process were considered the objective formula (1) and the demand of restrictions (2), orders (3), delivery (4), daily production by product (5) and unit (6), the amount of product per production unit (7), and the amount of production time in the shift (8).

$$
\begin{aligned}
& C T P \operatorname{lnt} t_{p c d u}=\operatorname{Min} \sum_{p} \sum_{c} \sum_{d} \sum_{u} \\
& \left(C s m p_{p}+\left(\frac{\text { Cmod }_{u}}{\mathrm{Hrtr}_{u}} * Q t h r_{p u}\right)+\left(\frac{C f i x_{u}}{\operatorname{Hrtr}_{u}} * Q t h r_{p u}\right)\right) \\
& \sum_{c} \sum_{d} \sum_{u} C T P \ln t_{p c d u} \geq \operatorname{Dmnd}_{p} \forall p \in \operatorname{Prod}(p) \\
& \sum_{d} \sum_{u} C T P \operatorname{lnt} t_{p c d u} \geq \operatorname{Qtpd}_{c p} \forall p \in \operatorname{Prod}(p), c \in \operatorname{City}(c) \\
& \sum_{d} \sum_{u} C T P \operatorname{lnt} t_{p c d u} \geq Q t p d_{c p} \forall p \in \operatorname{Prod}(p), c \in \operatorname{City}(c) \\
& \sum_{c} \sum_{u}(C T P l n t)_{p c d u} \geq \sum_{p}(Q t h r)_{p u} *\left(H r t r_{u}\right) \forall p \epsilon \operatorname{Prod}(p), d \epsilon \operatorname{Dias}(d) \\
& \sum_{c} \sum_{p}(C T P \operatorname{lnt})_{p c d u} \geq \sum_{p}(Q t h r)_{p u} *\left(\text { Hrtr }_{u}\right) \forall u \epsilon \operatorname{Unid}(u), d \epsilon \operatorname{Dias}(d) \\
& \sum_{c}(C T P l n t)_{p c d u} \geq(Q t h r)_{p u} *\left(H r t r_{u}\right) \forall p \in \operatorname{Prod}(p), d \in \operatorname{Dias}(d), u \in \operatorname{Unid}(u) \\
& \sum_{c} \sum_{p}(C T P \ln t)_{p c d u} x\left(\frac{1}{(Q t h r)_{p u}}\right) \leq\left(\operatorname{Hrtr}_{u}\right) \forall u \in \operatorname{Unid}(u), d \epsilon \operatorname{Dias}(d)
\end{aligned}
$$

At the end of the optimization routine from the logistical process plant resulted in the need for raw materials and the days that customer orders could 
be delivered. Accordingly, the optimization model for the logistics process of supply was developed by the objective function (9), by the variable inventory control of raw material (10) and restrictions need of raw material (11), by the security level (12), by the availability of transport modal (13) and the supply provider (14). The model of logistic distribution process was developed with the object-formula (15), with restrictions demand (16), the quantity of products per day and customer city (17) and availability of the mode of transport (18).

$$
\begin{aligned}
& (C T A b s t)_{t c d m}=\operatorname{Min} \sum_{t} \sum_{c} \sum_{d} \sum_{m}\left(\text { Vlun }_{c t}+\left(\text { Vlun }_{c t} * I c m s_{c}\right)+\right. \\
& \left(\frac{\left(\text { Dist }_{c m} * C s k m_{m}\right)}{Q l m p_{t} * V l m p_{t} * C a p c_{m}}\right)+\left(\frac{\text { Txem }_{m}}{Q l m p_{t}} * \frac{V l m p_{t}}{C a p c_{m}}\right) \\
& \operatorname{Invt}_{t c d m}=E f m p_{d t}+A b s t_{t c d}-\text { Cons }_{d t} \\
& \sum_{c} \sum_{d} \sum_{m} C T A b s t_{t c d m} \geq N e c s_{t} \forall t \in M t p r(t)
\end{aligned}
$$

$C T \operatorname{Abst}_{t c d m} \leq \operatorname{Aces}_{c m} * \operatorname{Abst}_{t c d} \forall t \in \operatorname{Mtpr}(t), c \in \operatorname{City}(c), d \in \operatorname{Dias}(d), m \in \operatorname{Mode}(m)$

$$
\begin{gathered}
\operatorname{Invt}_{t c d m} \geq N v m p_{t} \forall t \in \operatorname{Mtpr}(t), c \in \operatorname{City}(c), d \epsilon \operatorname{Dias}(d), m \in \operatorname{Mode}(m) \\
\sum_{m} C T A b s t_{t c d m} \leq A b s t_{t c d} \forall t \in \operatorname{Mtpr}(t), c \epsilon \operatorname{City}(c), d \epsilon \operatorname{Dias}(d)
\end{gathered}
$$

$$
C T D s t r_{p c d m}=\operatorname{Min} \sum_{p} \sum_{c} \sum_{d} \sum_{m}\left(\left(\frac{D s t r_{p c d}}{Q l p r_{p}} * \frac{V l p r_{p}}{C a p c_{m}}\right) * \frac{\operatorname{Dist}_{c m} * C s k m_{m}}{Q t p d_{c p}}\right)
$$

$$
\sum_{m} C T D s t r_{p c d m} \geq D s t r_{p c d} \forall p \in \operatorname{Prod}(p), c \in \operatorname{City}(c), d \in \operatorname{Dias}(d)
$$

$C T D s t r_{p c d m} \leq$ Aces $_{c m} * D s t r_{p c d} \forall p \in \operatorname{Prod}(p), c \in \operatorname{City}(c), d \epsilon \operatorname{Dias}(d), m \in \operatorname{Mode}(m)$

In spite of alternative combinations involving the transports and activities related to suppliers and customers were designed in a simplified simulated environment they provided students a large number of possibilities at the time of decision-making. Additionally, it is possible to use the simulation models to evaluate each step the influence of decisions in costs and indicators. Furthermore, the optimization model helped to indicate how close the student was from the optimized solution with the data previously informed. 
In the application of business games, some aspects such as knowledge of the operations of a company and problem-solving were considered important in the teaching-learning process. There was also conformity and consciousness of some students on learning in the decision-making process: decisions can influence the results more than others, "it was observed that small details may generates different paths and outcomes".

The use of simulation and optimization models in this research allowed that the options for decision-making and the results produced were built from a scientific perspective and not empirically. The simulation models helps to improve the decision-making process with fictitious situations to represent the reality of the business environment and students can virtually view the company's daily routine and interact in the process. Moreover, the optimization model helps finding out the best decisions based on the simulated scenario and to indicate the goal to be achieved in the teaching process.

\section{$5 \quad$ Final Remarks}

The use of simulation and optimization models in business games helps in the decision-making process and enhances the perception of students in how to manage a business. These models define the goal that students should reach and also demonstrate applied sciences to decision model [12]. Through the application of these models in business games it is possible to predict performance accurately within a certain range than to implement one optimal solution based on a fixed decision model [5]. The ways of using current technology platforms for business games have allowed modifying the evolution of the interaction and immediate feedback on the decision-making results. Therefore, participants will have a good opportunity to apply their learning outcomes in terms of decision analysis of business situation [14].

In this research, students would like to play again and recognize the contribution of business simulation games in learning process about decision-making. Students enjoy to play games and when they use business games may see the impact of decision immediately [8]. Educators are constantly striving to bring management education to close to reality [11]. Thus, Students perceived that over the use of business simulation games is possible to increase the knowledge about how to solve problems in logistics and how to operate the inner workings. Moreover, they recognize benefits but consider that it is difficult for them to truly understand the challenges and find out solutions [15], mainly in aspects related to instructions and the time available to perform the teaching activity.

Finally, business games are used as a teaching strategy at universities and the discussion on the use of this active learning methodology, as well its impact and contribution to the teaching process, has produced studies that demonstrate the importance of their evolution and adaptation to the innovations of information technology and communication. Furthermore, as suggestions for continuing this research, new routines as the decision model of implementation and financial module, reverse logistics and sustainability could be carried out. 


\section{References}

1. Ruben, B.D.: Simulations, Games, and Experience-Based Learning. Simulation Gaming 30(4), 498-505 (1999)

2. Zhao, E.: Business Logistics Costs Dropped in 2009. The Wall Street Journal (2010)

3. Thiers, G., McGinnis, L.: Logistics Systems Modeling and Simulation. In: Proceedings of Winter Simulation Conference (WSC). pp. 1531-1541. IEEE (2011)

4. Arisha, A., Young, P.: Intelligent Simulation-based Lot Scheduling of Photolithography Toolsets in a Wafer Fabrication Facility. In: Proceedings of Conference on Winter Simulation. pp. 1935-1942. IEEE (2004)

5. Tarokh, M.J., Golkar, M.: Supply Chain Simulation Methods. In: 2006 IEEE International Conference on Service Operations and Logistics, and Informatics. pp. 448-454. IEEE (2006)

6. Keys, B., Wolfe, J.: The Role of Management Games and Simulations in Education and Research. Journal of Management 16(2), 307-336 (1990)

7. Melnyk, S.A., Rodrigues, A., Ragatz, G.L.: Using Simulation to Investigate Supply Chain Disruptions. In: Zsidisin, G.A., Ritchie, B. (eds.) Supply Chain Risk, pp. 103-122. No. 124 in International Series in Operations Research \& Management Science, Springer US (2009), dOI: 10.1007/978-0-387-79934-6_7

8. Feng, K., Ma, G.: Evaluating Two Online Smulation Games in an Undergraduate Supply Chain Management Course. Review of Business Research 2(9), 67-75 (2009)

9. Mahfouz, A., Hassan, S.A., Arisha, A.: Practical Simulation Application: Evaluation of Process Control Parameters in Twisted-Pair Cables Manufacturing System. Simulation Modelling Practice and Theory 18(5), 471-482 (2010)

10. Iyer, A., Seshadri, S., Vasher, R.: Toyota Supply Chain Management: A Strategic Approach to Toyota's Renowned System. McGraw-Hill Education, New York, 1ed edn. (2009)

11. Doyle, D., Brown, F.W.: Using a Business Simulation to Teach Applied Skills: The Benefits and the Challenges of Using Student Teams from Multiple Countries. Jnl Euro Industrial Training 24(6), 330-336 (2000)

12. Deling, L., Liping, H., Zhongwei, L., Xuping, W.: Logistics Distribution Center Location Decision-making Model Based on Simulation Optimization. In: Proceedings of International Conference on E-Business and E-Government. pp. 3384-3387. ICEE '10, IEEE Computer Society, Washington, DC, USA (2010)

13. Arisha, A., Abo-Hamad, W., Ismail, K.: Integrating Balanced Scorecard and Simulation Modelling to Improve Emergency Department Performance in Irish Hospitals. In: Proceedings of Winter Simulation Conference. IEEE (2010)

14. Tobail, A., Crowe, J., Arisha, A.: Learning by Gaming: Supply Chain Application. In: Proceedings Winter Simulation Conference. pp. 3935-3946. IEEE (2011)

15. Sparling, D.: Simulations and Supply Chains: Strategies for Teaching Supply Chain Management. Supp Chain Mnagmnt 7(5), 334-342 (2002)

16. Davis, D.M., Gottschalk, T.D., Davis, L.K.: High-performance Computing Enables Simulations to Transform Education. In: Winter Simulation Conference. IEEE, Piscataway (2007)

17. Syrjakow, M., Berdux, J., Szczerbicka, H.: Interactive Web-based Animations for Teaching and Learning. In: Proceedings of Conference on Winter Simulation. vol. 2, pp. 1651-1659. IEEE (2000)

18. Alemany, M., Boj, J., Mula, J., Lario, F.C.: Mathematical Programming Model for Centralised Master Planning in Ceramic Tile Supply Chains. International Journal of Production Research 48(17), 5053-5074 (2010) 